\title{
Multi-speed Europe? An Analysis of the Real Convergence within the European Union
}

\section{Dumitru Miron and Ana-Maria Holobiuc}

The Bucharest University of Economic Studies, 6 Piata Romana, 1st district, Bucharest, 010374 Romania

\section{Abstract}

Reaching an appropriate level of economic, social and territorial convergence has been a strategic goal for European policy and decision-makers. The author's first assumption is that although in the early stages of the regional project, the Member States had similar growth and development levels, with the advancement of the integration process, the development asymmetries increased. In this paper, the authors stress the fact that the European decision-makers and researchers have become more and more interested to study if the Member States of the European Union meet the criteria for certain types of convergence: nominal, real, legal, structural and institutional. This paper brings to the fore-front the process of real convergence, trying to respond to the

Corresponding Author: Ana-Maria Holobiuc

anamaria_holobiuc@yahoo.com

Received: 17 November 2019

Accepted: 6 January 2019

Published: 12 January 2020

Publishing services provided by Knowledge

(c) Dumitru Miron and Ana-Maria Holobiuc. This article is

distributed under the terms of the Creative Commons

Attribution License, which

permits unrestricted use and redistribution provided that the original author and source are credited.

Selection and Peer-review unde the responsibility of the EBEEC Conference Committee. question if the Member States are catching-up, or are diverging. Moreover, taking into consideration the enlargement of the European Union with the countries from Central and Eastern Europe, we have studied the main trends within this group of countries. In this respect, we have calculated the $\sigma$ and $\beta$ convergence for three geographical clusters of countries: Central Eastern, North Western and Southern Europe. The results obtained show that the economies of the New Member States increased faster than those of the North Western countries, experiencing a significant speed of convergence. In contrast, the North Western countries recorded a negative pace in terms of convergence and significant discrepancies between them. In conclusion, the paper shows that the desiderate of real convergence becomes more and more difficult to achieve as while the Central and Eastern Europe states make important steps in reducing the disparities between them and also catching up with the European Union's average, the Southern Europe countries are diverging.

Keywords: European Union, real convergence, $\sigma$-convergence, $\beta$-convergence

\section{Introduction}

The fundamental principle for the European integration architecture has always been solidarity. In order to formalize this desideratum, a certain level of economic, social and territorial cohesion has been needed. The core of cohesion is convergence that can be nominal and real. A topic of great importance has been the mechanisms whereby the advancement of the integration process requires a certain level of convergence, but also contributes to the spillover effects generated by it. In this respect, one of 
the most important objective was to study how the poor economies are catching up to the level of rich ones. As the process of European integration progressed both on the deepening and enlargement dimensions, the concept of real convergence has become more and more debated both by decision-makers and scientists. The biggest challenge for the European decision-makers is to choose a development model - one centered on cohesion, one focused on competitiveness, or the optimal combination of them. In connection with this dilemma, the public, national and European agendas have expanded in the recent years, some figures militating for the idea of multi-speed or two-speed Europe, while others supporting cohesion and convergence between the Member States.

With the outbreak of the sovereign debt crisis in the EU, the European policymakers understood that the fulfilling of the nominal criteria does not guarantee that the states joining the euro area are really prepared to make this step. As a result, a paradigm change has taken place at the European level, in which the attention of political decisionmakers and analysts is gradually shifted from nominal to real convergence.

Taking into consideration the more and more sensitive challenges that the EU face, the authors of this paper try to respond to the question if the EU should be considered a two- or multi-speed power after the accession of the countries from the Central and Eastern or on the contrary, that it can become stronger. Consequently, the main hypothesis is that the new countries that joined the EU are making important steps in terms of reducing the disparities, while the old Member States are registering a divergence process also between them and the other groups of countries.

\section{Literature Review}

\subsection{The concept of real convergence}

At the beginning of the $21^{s t}$ century, European Union (EU) has been in full process of expansion and deepening, with the accession of Central and Eastern European countries and the strengthening of the Economic and Monetary Union. Aiming to improve their economic and social environment and to achieve the economic performances of the Western countries, 11 countries from Central and Eastern Europe joined the regional integration project.

With the subsequent stages of enlargement and the proves that the fulfillment of the Maastricht criteria is not enough to ensure a smooth integration of the states in the Euro area, experts started to pay more attention to the real convergence. Although 
there are no clearly defined criteria stated at the European level in order to define the real convergence, analysts identified some indicators representative for this process such as: real GDP per capita, the volume of the international trade, the costs of labor factor and the structure of economy.

According to some Romanian experts (Romanian National Commission for Forecast, 2018), real convergence defines the process of poor economies catching up to the level of rich economies or the process of reduction the gaps between countries in terms of living standards. With the deepening of the regional integration process and the enlargement of the EU, increasingly worrying realities emerged such as: the large gaps between states in the level of training and the occupational structure of the human resource; asymmetries in terms of labor productivity and external competitiveness of products and services; different availability of resources; different levels of density and quality of infrastructure networks; the share of sectors facing industrial decline but those belonging to the new quaternary sector of the economy. On this background, convergence has also aimed the capacity of candidate states to meet the accession criteria [1]. From another perspective (Björkstén, 2000), real convergence aims the reduction of the productivity gaps and price levels between countries, which take place a result of strengthening the economic integration between poorer and richer countries. According to Björkstén, with the increase in trade exchanges and technology transfers between countries, poorer companies reach the level of the more developed partners, recording higher price levels and productivity growth [2].

Besides the perspectives presented above, Żuk et al. (2018) brought to the forefront the concept of sustainable economic convergence. From this point of view, a (Euro Area) Member State must improve its institutional quality in order to record progresses in terms of convergence. In other words, strengthening the institutional governance will bring about economic growth and development. However, this not involves convergence towards a unique institutional model for all countries. According to the experts, sustainable convergence stresses the need to find solutions tailored to the particularities of the country [3].

From the perspective of Lee et al. (1997), real convergence can be analyzed from the perspective of three concepts: $\beta$-convergence, $\sigma$-convergence and club convergence [4]. According to Gligor and Ausloos (2008), $\beta$-convergence implies that poorer countries grow faster than rich ones, being a necessary but not sufficient condition for diminishing the disparities between them ( $\sigma$-convergence). However, although low-income countries may grow faster than those with high incomes, this may not be sufficient to balance incomes, so the real convergence process will occur [5]. A third notion of convergence 
identified by Lee et al. is referring to the model that treats the per capita result as an integrated variable and asks whether the different countries have a deterministic and a stochastic common trend [4]. Quah (1996) explained the existence of convergence clubs, namely the endogenous formation of coalitions. In this model, the developed countries or regions tend to get closer to the rich average position, while the poorest ones aim the average poor position [6].

\subsection{An analysis of the real convergence process in the Member States from Central and Eastern Europe}

With the last waves of enlargement of the EU, theoreticians and policy decision-makers both from Community and national bodies, have become more and more interested to study the economic background of these New Member States, including in terms of real convergence. Moreover, the economic performances of the old Member States that initially adopted the single currency have been debated in the last decade. In this respect, theoreticians such as Franks et al. (2010) [7], auf dem Brinke (2015) [8], Diaz del Hoyo et al. (2017) [9], van Loon (2018) [10] and Gros (2018) [11] studied the impact of the enlargement and deepening of the EU on the economic performances of the Member States.

Żuk and Savelin (2018) compared the economic performance of the Central, Southern and Eastern European countries with those of the Western Balkans. The experts from the European Central Bank (ECB) have shown that the catching up process in the new Member States has been generally faster than in the Western Balkans. New EU Member States, such as the Czech Republic, Slovenia and Sweden, have reached a GDP per capita of almost 90\% of the EU average in 2017 (Czech Republic -- 89\%, Slovenia 85\%). In contrast, all the economies in the Western Balkans had income levels of less than 50\% of the EU average in 2017 (Montenegro 46\%, Serbia 36\%) [3].

Diaz del Hoyo et al. (2017) illustrated that although the promotors of the single currency were expecting that entering the Eurozone will enhance the convergence between the participating countries, this goal was not accomplished so far. In this respect, it seems that early adopters (Austria, Belgium, Finland, France, Germany, Ireland, Italy, Luxembourg, Netherlands, Portugal, Spain, and Greece) recorded little progress in terms of catching up. Moreover, it seems that some of the initial countries with low incomes didn't succeed to reduce the disparities or even started to diverge (Spain, Greece) [9]. In addition, from van Loon's perspective, there has been no convergence between EU countries during four decades (1970-2010). However, it seems that 
before the crisis there was an income convergence between the countries of Eastern Europe that joined the Euro Area. The experts noted that both the non-euro new Member States and the euro new Member States had performed significantly better than the old Member States in terms of catching up [10].

Regarding the regional inequalities, Artelaris et al. (2010) empirically demonstrated that they increased significantly after the collapse of the communist regime in Central and Eastern Europe. In addition, the authors identified the existence of convergence clubs between regions from the new Member States [12]. Furthurmore, van Loon (2018) illustrated the existence of a convergence club within the EU. According to the other analysts, this club did not take place as a result of the adoption of the euro, but taking into consideration the administrative structure and type of capitalism [10].

\section{Methodology}

In order to test the hypothesis of the paper, namely if the Member States of the EU are catching up or are diverging, the authors made a comparative analysis between the GDP per capita in 2000 and 2017 in the case of the three groups of countries: from Central and Eastern, North Western and Southern Europe. Moreover, we have calculated the $\beta$ - and $\sigma$-convergence for three groups of countries mentioned above.

The tests of $\beta$ - and $\sigma$-convergence were used are used by experts to test the hypotheses of real convergence. $\beta$-convergence, a concept which derives from the neoclassical growth models, aims a potentially negative relationship between per capita growth and the initial level of income. According to this concept, the poorer countries will grow faster than the richer ones. In contrast, the concept of convergence implies that the international distribution of incomes diminishes over time [13]. According to Gligor and Ausloos (2008), $\beta$-convergence implies that the poorer countries grow faster than the rich ones, this fact being a necessary but not a sufficient condition for the reduction of the disparities between them ( $\sigma$-convergence). Consequently, although low-income countries may grow faster than those with high incomes, this may not be sufficient to equalize the incomes, so the real convergence process occur [4]. 


\section{Results}

\subsection{From the GDP per capita perspective}

Figure 1 shows the values of GDP per capita in 2000 and 2017 in the case of the ten countries that joined the EU in 2004, Romania and Bulgaria (2007) and Croatia (2013). During the analyzed period, the most important increases in terms of GDP per capita were recorded by Romania (142\%) and Lithuania (110\%). Also the other two Baltic states recorded important increases in terms GDP per capita of 92\% (Estonia) and 91\% (Latvia). Countries from Central and Eastern Europe that recorded the lowest increases in GDP per capita during the 18 years are: Croatia (29\%), Czech Republic (25\%), Slovenia (6\%). In spite of the modest growth, Czech Republic had in 2017 the highest value of GDP per capita in the group of countries from Central and Eastern Europe, representing 89 PPS.

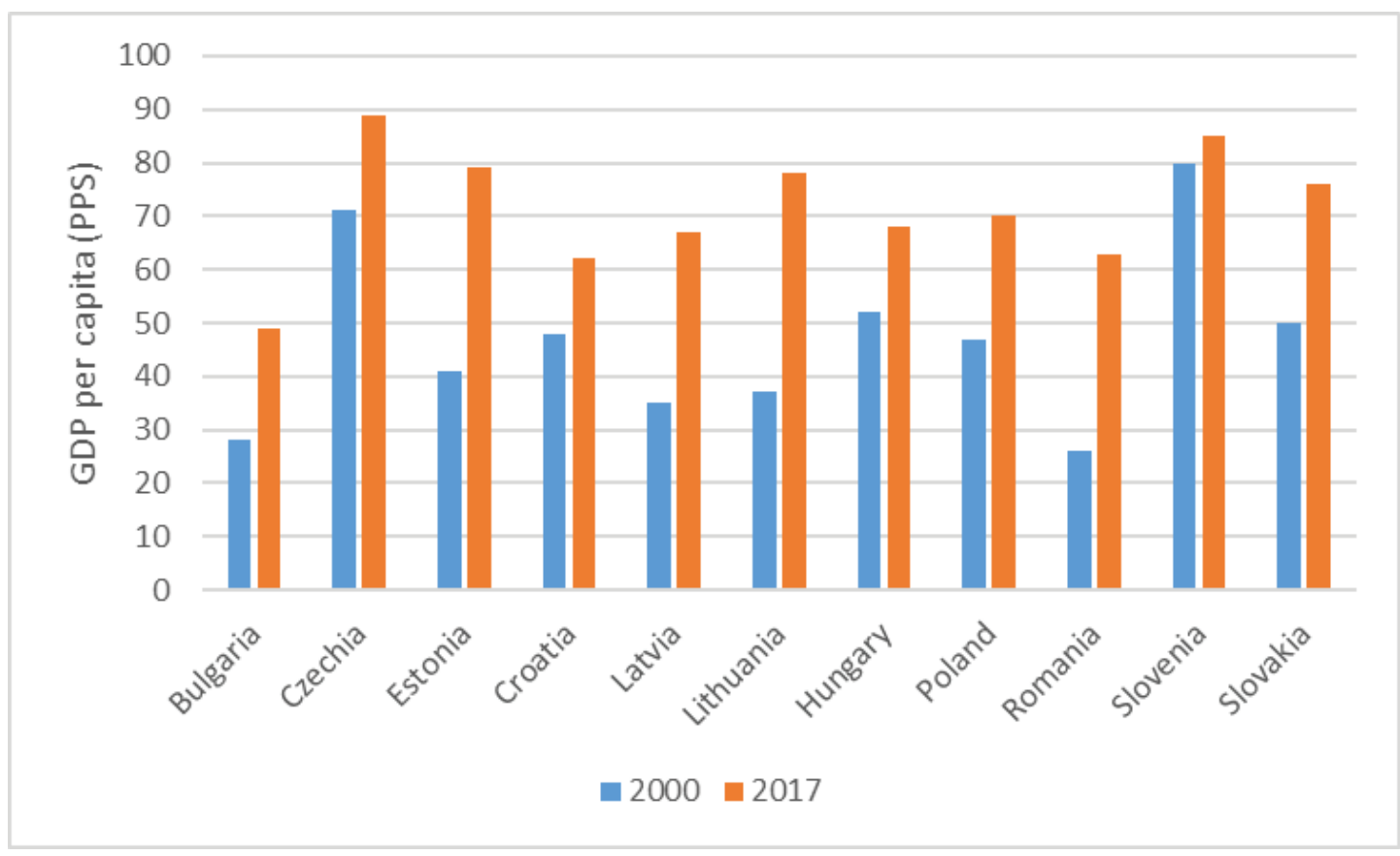

Figure 1: The GDP per capita in the countries from Central and Eastern Europe in 2000 and 2017 (Source: Author's processing based on data provided by Eurostat).

In contrast, the countries from North Western Europe had on average negative performances. For example, France, United Kingdom and Netherlands recorded a GDP per capita decrease of almost $10 \%$ in 2017 comparing to 2000 . Countries that had a small, but positive performances were Denmark (from 127 PPS to 128 PPS), Germany (from 122 PPS to 124 PPS) and Luxembourg (244 PPS to 253 PPS). A significant performance in this group of states was recorded by Ireland, with a value of 181 PPS in 2017, comparing with 122 in 2000. In this group, except Sweden and United Kingdom, all the countries 
were early adopters of the Euro currency. Taking into consideration the regression in the case of GDP per capita from 2000 to 2017, we conclude that the single currency did not lead in the case of the early adopters to better economic performances.

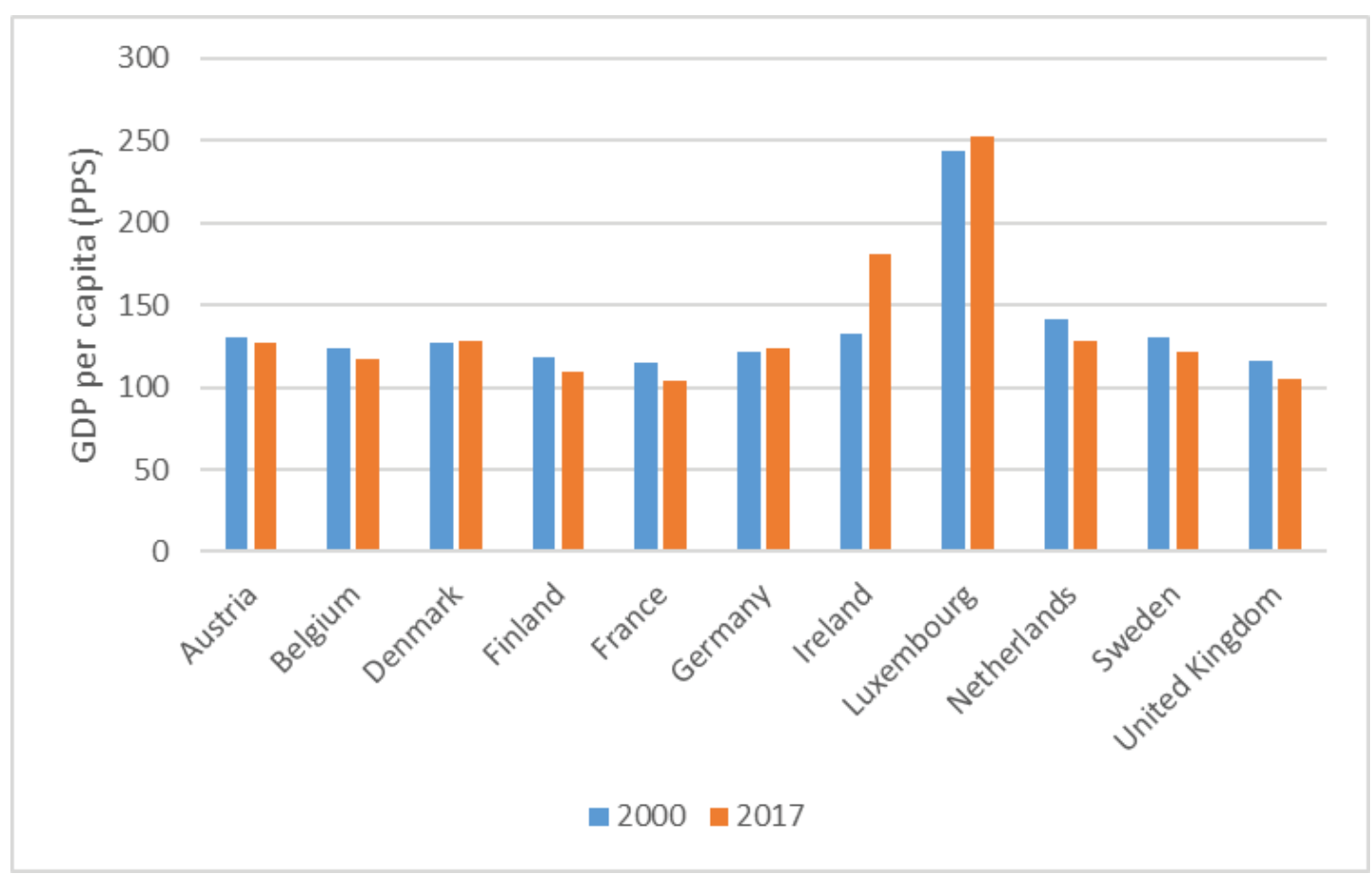

Figure 2: The GDP per capita in the countries from North Western Europe in 2000 and 2017 (Source: Author's processing based on data provided by Eurostat).

As far as the group of countries from Southern Europe is concerned, Figure 3 shows the GDP per capita in 2000 and 2017. According to the data provided by Eurostat, Malta was the only country from this group that recorded an evolution in terms of GDP per capita from 2000 to 2017 of $18 \%$. The rest of the countries from southern Europe recorded a negative trend in terms of GDP per capita: Spain a decrease of 3\% (from 95 PPS to 92 PPS), Portugal a decrease of 6\% (from 83 PPS to 77 PPS), Cyprus of 9\% (from 94 PPS to 85 PPS), Italy of 20\% (from 119 PPS to 96 PPS) and Greece of 23\% (from 86 PPS to 67 PPS)

\subsection{From the $\beta$-convergence perspective}

The figure below illustrates the $\beta$-convergence for the EU Member States. The negative slope illustrates that countries with lower initial income grew faster between 2008 and 2017. Consequently, the most important performances were recorded by the countries included in the Central and Eastern group: Romania (5.22 \%), Poland (4.24\%), Lithuania, (4.12\%), Bulgaria (3.59\%), Latvia (2.99\%), Slovakia (2.78\%) and Estonia (2.69\%). As far 


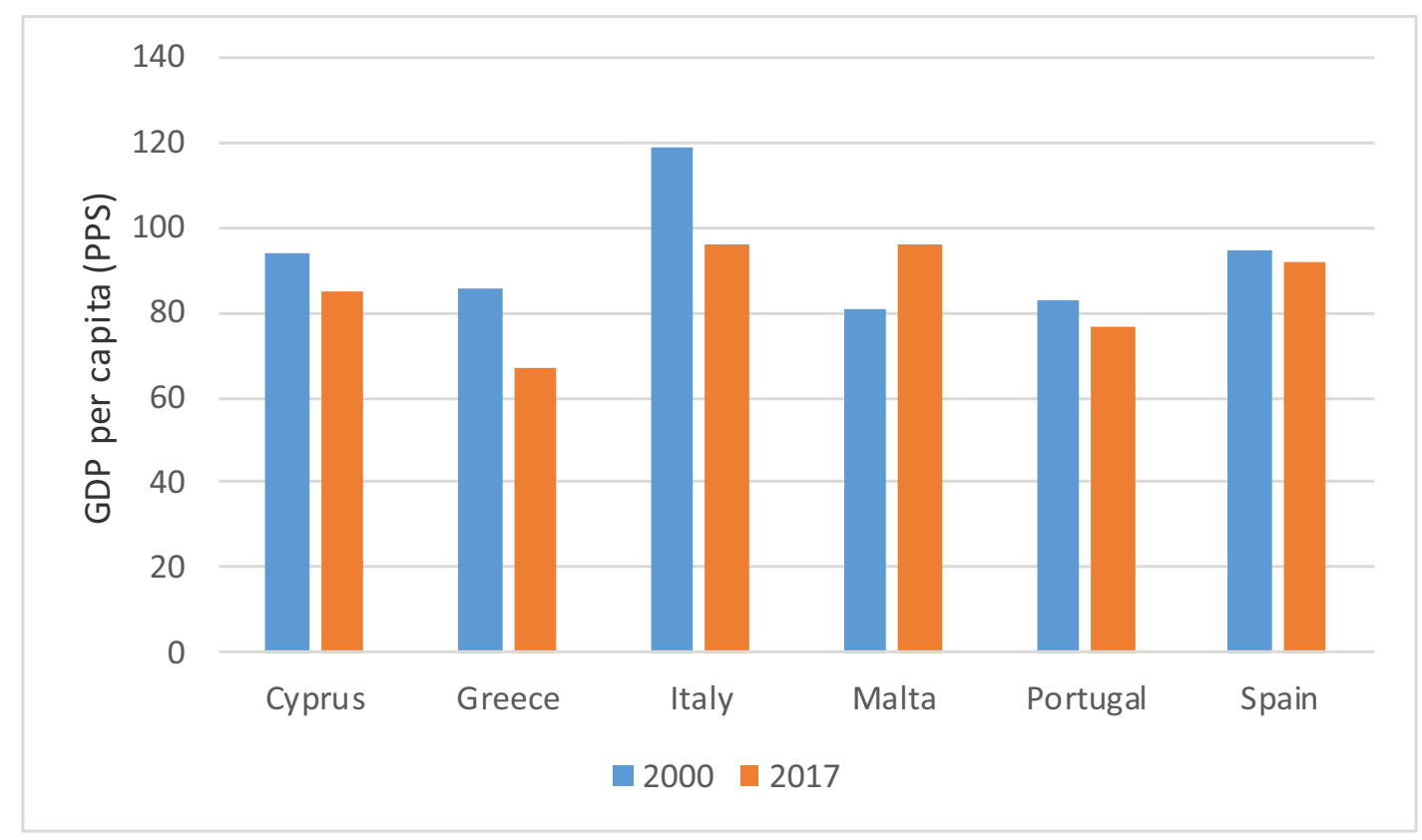

Figure 3: The GDP per capita in the countries from Southern Europe in 2000 and 2017 (Source: Author's processing based on data provided by Eurostat).

as the North Western group is concerned, it seems that all the countries had positive performances. The high GDP increase over the period was recorded by Ireland (3.5\%), this country being followed by Germany (1.98\%), Denmark (1.81\%), Austria (1.60\%), Belgium (1.42\%), France (1.05\%). The rest of the countries included in this group had a GDP growth below $1 \%$. In the Southern Europe group, apart from Malta that had an important GDP increase (3.64\%), the rest of the countries had modest or even negative performances. For example, Portugal a GDP growth of $0.82 \%$, Italy $0.35 \%$ and Spain $0.26 \%$. Cyprus and Greece had GDPs decreases of $0.65 \%$ and respectively, $1.75 \%$.

\subsection{From the $\sigma$-convergence perspective}

Figure below shows the coefficient of variation in the case three groups analyzed above and the EU (28). In the case of the EU, during the 10-year analyzed was recorded a stable trend, as in 2008, $\sigma$-convergence was 0.43, while in 2017 0.41. Consequently, in the case of the European bloc analyzed as a whole, there are no significant evidences that the discrepancies between countries declined. As far as the Central and Eastern Europe group is concerned, it seems that the discrepancies between countries have diminished from 2007. Consequently, in case of this countries, $\sigma$-convergence has been taking place. 


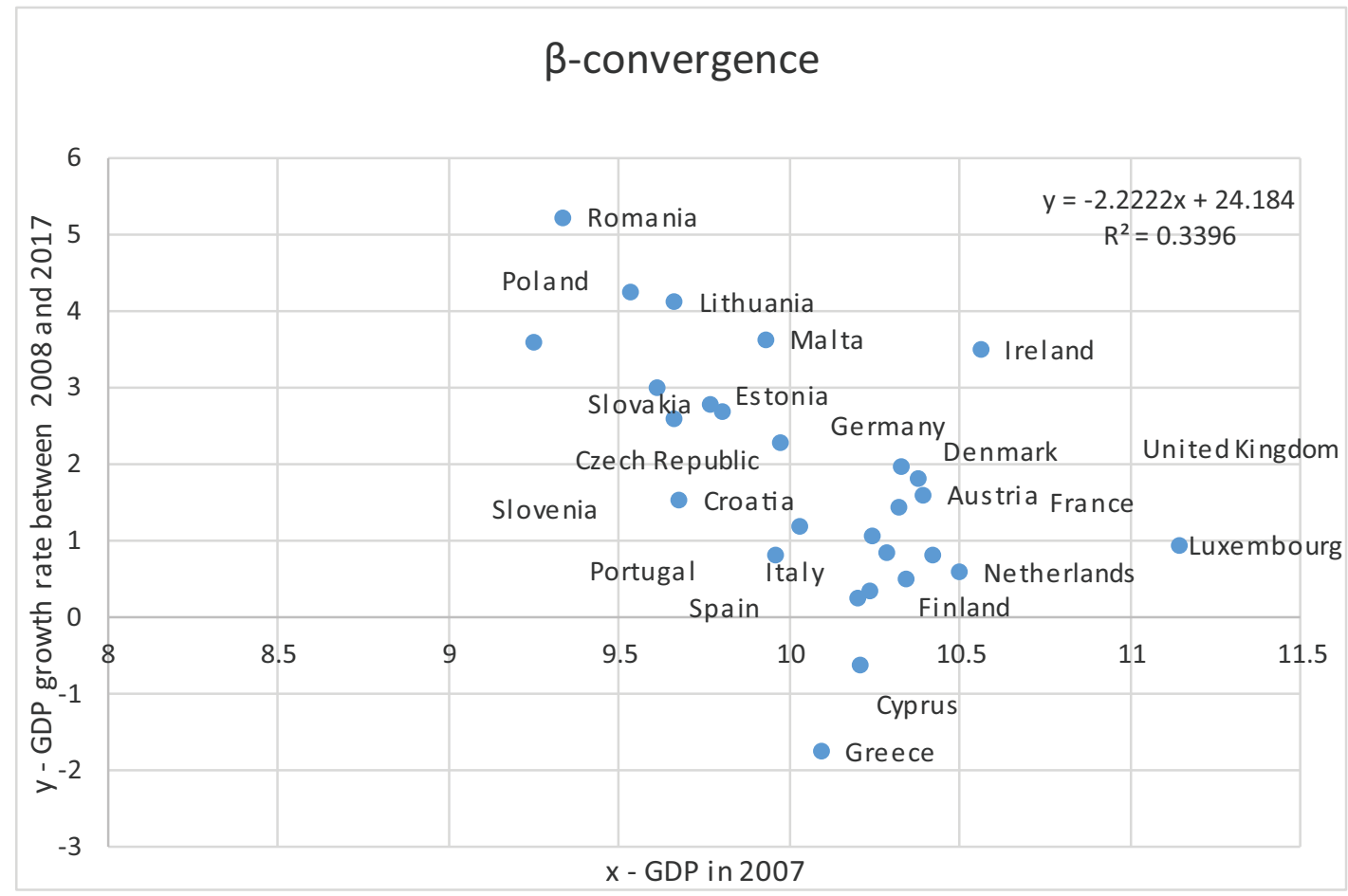

Figure 4: $\beta$-convergence of the GDP for the Member States of the EU (Source: Author's processing).

In the case of the North Western group, no clear evidences supporting $\sigma$-convergence were found, as there were similar values during the analyzed period. A similar situation can be find in the case of the Southern Europe countries. The value recorded in 2017 (0.14) is close to that from 2000 (0.13), showing that no clear improvements in terms of catching up between countries took place.

We can underline that in the case of the countries from Central and Eastern Europe, both the $\beta$ - and $\sigma$-convergence hypotheses are true. In this respect, economies that had lower initial GDP increased faster than the countries with higher performances. Moreover, with the increase in GDP, the divergence between countries reduces. As far as the North Western countries are concerned, although they had important GDP per capita increases, the group is still diverging. The countries from Southern Europe recorded over time modest economic performances or even negative, the $\beta$-convergence in this case being rejected. Based on these findings, we argue that countries from Central and Eastern Europe had the most significant performances, both in terms of enhancing their GDP and reducing the disparities. 


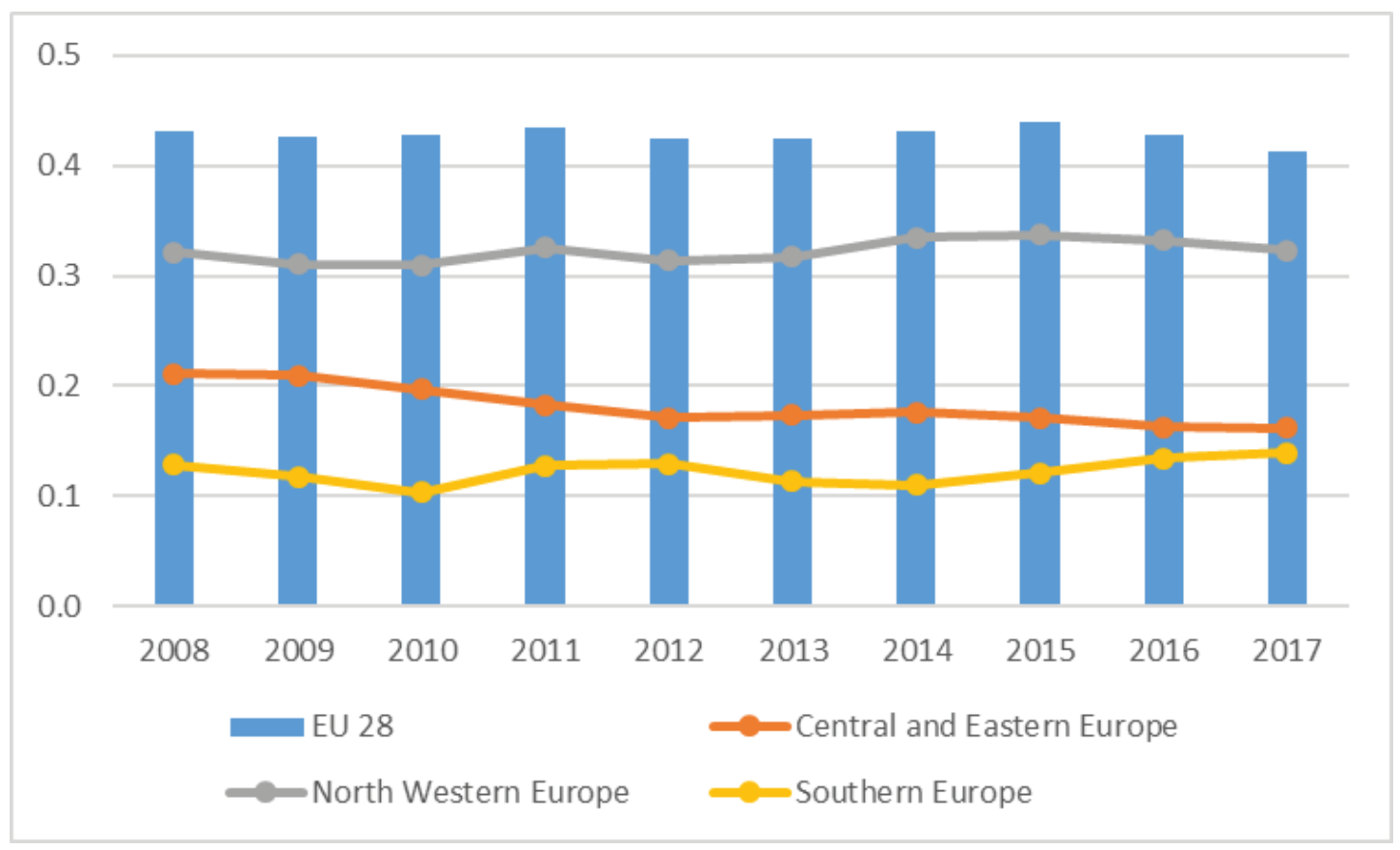

Figure 5: The $\sigma$-convergence (Source: Author's processing).

\section{Conclusion}

In conclusion, based on our calculations, having as analytical and methodological target real convergence, we offer few arguments for the question if the Member States are catching-up, or are diverging. Our analysis illustrates that the Central and Eastern group recorded important economic performances in terms of GDP per capita. Consequently, the $\beta$-convergence hypothesis was true. Moreover, the discrepancies between the Member States from this group diminished over time ( $\sigma$-convergence). As far as the North Western group is concerned, the Member States recorded on average a negative trend in terms of GDP per capita during the 10-year period. However, the discrepancies between the countries from this group of states are the higher than from the other two groups, so the $\sigma$-convergence hypothesis was rejected. Referring to the Southern Europe counties, they generally had modest performances or even negative. However, the convergence between this group of states is higher than in the case of the other groups.

Overall, it seems that although with the enlargement of the EU with the countries from Central and Eastern Europe, some voices argued that this step will negatively influence the prosperity of the region, this group of countries have made important progresses. In contrast, the countries from Southern Europe are on a downward trend in terms of economic performances, while the North Western group is threatened by prominent discrepancies between the countries. 


\section{References}

[1] Romanian National Commission for Forecast, 2018. Real convergence. Retrieved from: http://www.cnp.ro/user/repository/ConsiliulProgramareEconomica/ convergenta_reala.pdf

[2] Björkstén, N. 2000. Real convergence in the enlarged euro area: a coming challenge for monetary policy. Bank of Finland Economics Department Working Papers, No 1. Helsinki.

[3] Żuk, P., Savelin L., 2018. Real convergence in central, eastern and south-eastern Europe. ECB Occasional Paper Series No. 212. European Cemtral Bank, Frankfurt.

[4] Lee et. al, 1997. Growth and Convergence in a Multi-Country Empirical Stochastic Solow Model. Journal of Applied Econometrics, Vol. 12, pp. 357-392

[5] Gligor, M \& Ausloos M. 2008. Convergence and Cluster Structures in EU Area according to Fluctuations in Macroeconomic Indices, Journal of Economic Integration, Vol. 23, No. 2, pp. 297-330

[6] Quah, D. T, 1996. Empirics for economic growth and convergence, European Economic Review, Vol. 40, Issue 6, pp. 1353-1375.

[7] Franks, J. et al, 2018. Economic Convergence in the Euro Area: Coming Together or Drifting Apart? IMF Working Paper International Monetary Fund: Washington.

[8] Auf dem Brinke, $A$ et al, 2015. What kind of convergence does the Euro area need?, Güters/oh: Bertelsmann Stiftung und Jacques Delors Institut: Berlin. Retrieved from: https://www.delorsinstitut.de/2015/wp-content/uploads/ 2015/12/Convergence-Study-Final.pdf.

[9] Diaz del Hoyo et al, 2017. Real convergence in the euro area: a long-term perspective. European Central Bank. ECB Occasional Paper Series, 203. Frankfurt: European Central Bank.

[10] Van Loon, Y, 2018. Economic convergence as the cornerstone of EMU resilience Indicators, institutions and instruments. Clingendael Report. Netherlands Institute of International Relations Clingendael, Netherlands.

[11] Gros, D. (2018). Convergence in the European Union: Inside and outside the Euro. Centre for European Policy Studies, Bruxelles

[12] Artelaris, et al, 2010. Regional Inequalities and Convergence Clubs in the European Union New Member-States. Eastern Journal of European Studies, Vol.1, Issue 1, pp. 113-133, Centre for European Studies, Alexandru Ioan Cuza University: Iași.

[13] Alcidi, C. et al, 2018. Income Convergence in the EU: A tale of two speeds. Centre for European Policy Studies, Bruxelles 